\title{
Por qué el periodismo ciudadano no es una amenaza para la industria de la prensa: la producción cultural del usuario frente a las industrias culturales
}

\author{
José Patricio PÉREZ RUFÍ \\ Universidad de Málaga \\ patricioperez@uma.es \\ Francisco Javier GóMEz PÉREZ \\ Universidad de Granada \\ frangomez@ugr.es \\ José Luis NAVARRETE CARDERO \\ Universidad de Sevilla \\ lnavarrete@us.es
}

Recibido: 10 de septiembre de 2014

Aceptado: 22 de enero de 2015

\begin{abstract}
Resumen
Este estudio pretende demostrar que la participación ciudadana en la creación de contenidos culturales no supone la amenaza que se le suponía para las industrias de la comunicación, ni mucho menos para los medios informativos digitales pertenecientes a los grandes grupos de comunicación. La producción cultural del usuario no supondría tal amenaza desde el momento en que el nivel de implicación del usuario en su creación es muy superficial, al tiempo que su alcance será mucho más limitado. La posible competencia del periodismo ciudadano no provoca así la crisis en la prensa industrial.

Palabras clave: industrias culturales, periodismo ciudadano, contenidos generados por usuarios, redes sociales, grupos multimedia.

\section{Why the Citizen Journalism does not constitute a threat for the Press Industry. The user cultural production facing the Cultural Industries}

\begin{abstract}
This paper tries to demonstrate that the participation of the citizen in the creation of cultural contents does not constitute a threat to the communication industries, far from digital information media linked to media groups. The user cultural contents do not suppose that threat because of the superficial commitment of the users in their generation and the short significance of his production, lower than the media brands. The possible competition of citizen journalism is not the reason of the crisis in the industrial press.

Keywords: cultural industries, citizen journalism, user generated contents, social networks, media groups.

\section{Referencia normalizada}

PÉREZ RUFÍ, José Patricio; GÓMEZ PÉREZ, Francisco Javier; y NAVARRETE CARDERO, José Luis (2015): "Por qué el periodismo ciudadano no es una amenaza para la industria de la prensa: la producción cultural del usuario frente a las industrias culturales". Estudios sobre el Mensaje Periodístico. Vol. 21, Núm. 2 (julio-diciembre), págs.: 899-912. Madrid, Servicio de Publicaciones de la Universidad Complutense.
\end{abstract}

Sumario: 1. Introducción. 2. El usuario productor de contenidos: ¿hace periodismo el infociudadano? 3. Resultados (I): La implicación del usuario en la generación de contenidos. 4. Resultados (II): El alcance de los medios de los usuarios. 5. Conclusiones. 6. Referencias bibliográficas. 


\section{Introducción}

La raíz última de la revolución digital que ha cambiado el concepto, la naturaleza, los procesos e incluso el lenguaje de la producción cultural se encuentra en la confluencia de diversos factores de índole tecnológicos, junto a una demanda de participación en la creación de contenidos. La convergencia digital de medios, el acceso popular a la tecnología de producción, la facilidad en la gestión de la información y la difusión masiva e inmediata de dicho material, cualquiera que sea su soporte, a través de Internet, han provocado una revolución que ha alterado las bases de las industrias culturales, ha introducido nuevos agentes en el sistema y ha condicionado a las industrias culturales a adaptarse a sus demandas.

Para los nuevos productores de contenidos ha dejado de ser condición sine-qua la formación y la especialización en la creación de información (es decir, la profesionalidad), imprescindible previamente para el acceso a los medios. Al margen de los criterios que tradicionalmente limitaban la posibilidad de una comunicación masiva por parte del ciudadano, los nuevos agentes de la comunicación han hecho uso de todas las opciones que las nuevas herramientas de comunicación les permiten, favoreciendo la difusión de contenidos, el feedback inmediato y una interacción que crea redes sociales y comunidades de usuarios con inquietudes semejantes. De ello deviene una supuesta horizontalidad con los medios en la propagación de un discurso personal -aunque homogeneizado en líneas generales a los criterios sociales propagados por otros medios- y una paralela saturación de información que dificulta su localización y su posible utilidad. Dejar la creación de información en manos de usuarios sin una formación capacitada para ello produce la difusión de informaciones de mala calidad, no contrastadas, interesadas y, de forma consecuente, desinformación y manipulación.

Autores como Keen (2007) han rechazado la idea de la posición privilegiada del usuario: iría en detrimento de las industrias culturales establecidas y, con ello, de toda la cultura creada por los profesionales de la misma. Hablaríamos en este caso de un "culto" a lo amateur, donde el aficionado alcanza la categoría de experto sólo por disponer de las herramientas de producción, edición y divulgación del profesional.

En este sentido, Martin Hirst (2011: 108), investigando acerca del futuro del periodismo en relación con la actividad del usuario, plantea la cuestión de que si todo el mundo es periodista, ¿quién es entonces la audiencia? Hirst advierte así del peligro de convertir la esfera pública en una torre de Babel.

Una objeción que podemos hacer a la horizontalidad de medios y usuarios en la comunicación digital está en que más allá de la propia producción y difusión de información, la industria cuenta con unas herramientas para popularizar y comercializar un producto no disponible para el usuario. Este hecho limita la expansión de los contenidos generados por usuarios, dado que se pierden en el océano de datos que supone Internet, hasta llegar a perder su utilidad.

La hipótesis de la que parte este estudio es que la participación ciudadana en la creación de contenidos culturales -o de información, de forma más específica- no supone una amenaza para las industrias de la comunicación, ni mucho menos para los medios informativos igualados en formato, como es la prensa digital. Las razones, como intentaremos demostrar, se encuentran tanto en el nivel de implicación de los usuarios 
en la generación de contenidos (muy superficial y ligada a un grupo muy minoritario, aunque activo), como en el alcance de dicha producción, inferior al de marcas con mejor posicionamiento.

Nuestros objetivos pasan por demostrar que las herramientas de creación y divulgación de contenidos por parte del usuario no han tenido la repercusión ni los efectos esperados, de donde se reafirmaría el rol principalmente pasivo y poco interactivo de aquel. Simultáneamente, intentaremos confirmar la preeminencia de las industrias culturales, sean del orden que sean, como marcas de referencia a las que acude el usuario en su búsqueda de contenidos o, de forma más específica, de información.

A fin de lograr dichos objetivos, y una vez enunciado un marco teórico que contextualice nuestra investigación, estableceremos una estrategia de investigación estructurada en dos partes; en primer lugar, atenderemos, a partir de los estudios de varias consultoras, al análisis de la implicación del usuario en la producción de contenidos según el modelo de formato o de participación; en segundo lugar, nos serviremos de la ayuda de herramientas de medición del alcance de los contenidos online para conocer la cobertura y audiencia de sites ligados a la producción del usuario, que contrastaremos con los datos acerca de la difusión de aquellos procedentes de las grandes industrias culturales en el medio digital; contrastaremos las conclusiones de las partes anteriores, desde el posicionamiento de los portales con contenidos generados por usuarios, ligados a las industrias culturales o con ambos rasgos como elementos definidores.

Partiremos pues de una metodología eminentemente cuantitativa que, no obstante, habrá de complementarse con el análisis y una interpretación de resultados, para no quedarse en la mera descripción. Los antecedentes y fuentes de este estudio procederán del campo de la investigación de marketing online, así como de referentes en el estudio de la comunicación digital como Jenkins, Tancer o Nielsen y, de forma más específica, de textos acerca del periodismo ciudadano de Hirst, Bruns y Highfield o Katz, junto a informes procedentes de la Asociación para la Investigación de los Medios de Comunicación, el portal Alexa.com o la consultora The Coctail Analysis.

\section{El usuario productor de contenidos: ¿hace periodismo el infociudadano?}

La digitalización de las comunicaciones ha hecho converger en una misma matriz elementos sociales y tecnológicos que han dado lugar a un nuevo contexto mediático donde siguen en juego las posiciones de cada una de las partes implicadas y sus efectos. Encontramos así nuevos soportes y plataformas de distribución de contenidos, nuevos intermediarios, nuevos agentes en la producción, nuevos hábitos de consumo y la necesidad de readaptación de industrias culturales y ciudadanos ante las alternativas que se imponen frente a los medios tradicionales.

Las posibilidades de los medios digitales que facilitan la creación de contenidos por parte del usuario proceden de una evolución tecnológica puesta al servicio del internauta/consumidor, pero al mismo tiempo, citando a Henry Jenkins (2007: web), es el resultado de la necesidad de participación cultural de todo tipo durante décadas pasadas la que ha establecido el desarrollo y la rápida adopción de plataformas como YouTube, con lo cual podemos concluir que la tecnología responde a las demandas de la sociedad, y no al contrario. 
Internet y los servicios que permite se reivindicaron como el medio de los ciudadanos, convertidos en usuarios con capacidad de decisión y de elección no sólo en el consumo de información, sino también en la producción de la misma. Fernando Sáez Vacas (2007: 3) destaca el hecho de que se trata de usuarios y no de programadores, a los que convierte en infociudadanos. Aunque, como aquí sostenemos, la realidad acerca del uso de las mismas nos está mostrando que poco tiene que ver con una verdadera democratización de los medios o con una horizontalidad en la creación y difusión de contenidos, es innegable que la penetración de los medios digitales ha cambiado la dirección en la creación de tendencias, de temas de actualidad, de modas y de corrientes de opinión pública.

Es gracias a la convergencia de medios que procura la transición al digital que el usuario-infociudadano se convierte en creador de contenidos actualizables con periodicidad: prácticamente cualquier usuario con una infraestructura mínima puede producir contenido y divulgarlo de forma global.

El usuario se convierte en un eslabón en la cadena de difusión de información, yendo más allá de su mera articulación como receptor final en un proceso de comunicación. Por encima de sus posibilidades de interacción, de feedback o de producción de nuevos contenidos, el usuario colabora de un modo más o menos consciente en la divulgación de informaciones que, como la mecha de la pólvora una vez encendida, corre de internauta en internauta, creando nuevos referentes comunes en la comunicación.

La novedad que las herramientas sociales de creación de información y conocimiento han aportado ha sido la inversión en la dirección del sentido de la información, dado que en lugar de ir en sentido vertical de arriba abajo, la información puede ir de abajo a arriba yendo de los usuarios a los medios. Una vez que la información ha "ascendido" a los medios convencionales y sus editores deciden integrarla dentro de la agenda pública, dicha producción informativa es difundida por canales masivos que llegan a mayor número de receptores y es "devuelta" a la web y a sus usuarios. Muy habitualmente este nuevo producto/información es reelaborado por los medios para ser difundido de forma masiva, aunque en ocasiones sin haber sido contrastados.

Otro de los peligros que presenta este modo de distribución de contenidos es la rapidez de su caducidad, dado que la sucesión incesante de nuevas imágenes, informaciones o vídeos obliga a actualizar tanto al medio difusor como al usuario, devorador de información inmediata: la posibilidad de adelantarse a otros a través en la posesión de tal información le otorga un valor diferencial así a su favor.

¿Deberíamos llamar "periodismo" a la práctica del ciudadano en la creación de contenidos informativos? La respuesta no es sencilla ni permanente y el debate no permite llegar a resultados concluyentes. Puente y Grassau (2011: 139) parten de una definición operacional según la cual periodismo ciudadano sería la práctica informativa de los ciudadanos no profesionales del periodismo que cumple una serie de condiciones relativas a la táctica de su producción, la relación con las fuentes y el estilo e intención. Finalmente, concluyen que los ciudadanos no tienen "ni el deber, ni el compromiso ni las posibilidades de acceso a la información que les permitan cumplir a cabalidad con la responsabilidad social que define al periodismo" (Puente y Gras- 
sau, 2011: 151), razón por la cual terminan denominando como "dos términos contradictorios" al "periodismo ciudadano". Pellegrini (2010: 272) niega igualmente la existencia hasta el momento de una definición satisfactoria ni comprensiva del fenómeno, aunque recoge como la más precisa aquella que lo describe como "el acto en el que uno o un grupo de ciudadanos tienen un papel activo en el proceso de recolectar, analizar y diseminar noticias e información con el objetivo de entregar (...) la información que una democracia necesita". José María Perceval apunta a que la idea de "periodismo ciudadano" se trata la unión de ambos términos es un oxímoron, "ya que el periodismo está incluido en la ciudadanía y no al contrario" (Perceval, 2008: 84). Bruns y Highfield (2012: 20) son más prudentes al respecto y prefieren referirse a las creaciones informativas de los usuarios como "contenidos casi-periodísticos". Concluimos que aunque los diferentes estudios acerca del concepto se aproximan a la descripción del fenómeno, la concreción del concepto resulta compleja dada la imprecisa delimitación de las características que lo definen.

Ante las dificultades que ofrece el establecimiento de unos criterios que nos permitan definir como periodismo o no la producción del usuario, preferimos ampliar el concepto para abarcar toda la producción cultural del ciudadano, con independencia de su formato, de las características de su discurso o de las condiciones extradiscursivas en las que fueron realizadas. En este sentido, consideramos, por genérico, más completo el concepto de Castells (2009: 88) de autocomunicación de masas, como desarrollo de redes de comunicación horizontal a través de Internet, potencialmente masivas, pero simultáneamente personal desde el mismo momento en que el nuevo comunicador genera el mensaje, define los posibles receptores y selecciona los mensajes concretos o los contenidos de la web y de las redes de comunicación electrónica que quiere recuperar.

Una revisión bibliográfica acerca de la cuestión nos lleva a un debate inconcluso en la que los diferentes autores que la estudiaron se decantan por una consideración del periodismo ciudadano como complementario de la prensa industrial o, directamente, como sustituto de la misma. A partir del análisis de la cobertura informativa de la política local en diversos medios creados por usuarios y en prensa industrial, Fico et al. (2013: 166) entienden las webs de periodismo ciudadano como sustitutas imperfectas para la prensa, a pesar de las ventajas de dichos espacios digitales para determinadas comunidades. Asimismo, sostienen que no son muchas las diferencias entre los sites de información creados por usuarios y los blogs, pero sí entre estos medios y los periódicos, de donde se deduce una ventaja diferencial para la prensa. Hirst (2011: 122) aboga igualmente por la idea de que los medios sociales no son -"todavía", puntualiza- periodismo.

Desde otra perspectiva, Katz (2011: 60) mantiene que los medios sociales, como reto para la profesión del periodista, erosionan el rol democrático que tradicionalmente ha desarrollado el periodismo, pero apunta a que son también capaces de sustituirlo a través de sus actuaciones. Más moderados en este debate, Bruns y Highfield (2012: 1) llaman a una postura más realista acerca de las consecuencias de la irrupción de la tecnología digital en la creación y difusión de información, poniendo el acento en el espacio que comparten para ello antes que en las diferencias entre ambos. 
Desde aquí consideramos que la producción del usuario, cualquiera que sea la materia, informativa o no, que tome, no supone una verdadera competencia para las industrias culturales y que éstas mantienen una posición privilegiada y vertical -pese al uso de vías de comunicación de vuelta con el usuario- con respecto a la audiencia. La crisis actual en que se ven envueltos los medios procede de razones estructurales y económicas más profundas; la convergencia digital de aquellos y su distribución a través de Internet ha modificado el modelo de negocio y obliga a los medios a adaptarse a la nueva realidad tecnológica, dentro de la cual la actuación del usuario en aspectos productivos es influyente, pero no determinante. Nos apoyaremos en varios argumentos para sostener nuestra hipótesis.

\section{Resultados (I): La implicación del usuario en la generación de contenidos}

Estructuraremos el análisis desde dos perspectivas: una atiende a la implicación del usuario en la generación de contenidos, a partir de la cual conoceremos el nivel de compromiso de éste con la divulgación de material propio; la otra aborda el alcance de los medios que crea, de donde podríamos evaluar el impacto social de dichos contenidos en relación con la influencia de los medios ligados a las industrias culturales.

Acerca de la implicación del usuario en la producción de material, debemos en primer lugar mencionar a Jakob Nielsen (2006: web), quien formuló la regla 90-9-1, según la cual el $90 \%$ de los usuarios de la Web 2.0 son lurkers o lectores pasivos que observan pero no contribuyen, el $9 \%$ contribuye de forma muy esporádica, aunque otras prioridades ocupan su tiempo, y un $1 \%$ restante de usuarios participa activamente generando contenidos. Esta regla merecería de una actualización, dado que se trata de una estadística de 2006, año en el que muchas de las nuevas aplicaciones apenas iniciaban su andadura y no gozaban de la popularidad y reconocimiento que tendrían años después.

Bill Tancer (2008: 125), gerente general de la consultara Hitwise, fue más allá en su intento de confirmación la regla 90-9-1 en el caso concreto de portal UGC YouTube, comprobando que sólo el $0.16 \%$ de las visitas fueron para "subir" contenidos de vídeo. Hemos de apuntar que desde que Google adquirió YouTube dejaron de ser públicos los datos estadísticos acerca del volumen de visionados, tráfico de datos, número de usuarios e ingresos o beneficios del portal de vídeo, más allá de contados comunicados públicos en los que publicitar los logros de la empresa. Dada la opacidad de la empresa a la hora de comunicar datos más precisos y concretos acerca de la divulgación de los documentos audiovisuales dispuestos por el canal, es por ello que atendemos a Nielsen o Tancer. Apostamos, basados en ambos estudios, por el mantenimiento de la regla 90-9-1 también en lo relativo a contribución del usuario de YouTube a través de la producción y divulgación de material propio, como en parte veremos a partir de las informaciones que citaremos.

Llevado a la situación precisa en España, no poseemos datos acerca de la capacidad de producción de los usuarios españoles, aunque sí disponemos de las encuestas realizadas por la AIMC (Asociación para la Investigación de los Medios de Comunicación), responsable de los estudios de la Encuesta General de Medios y de los informes Navegantes en la red, orientados al conocimiento del consumo del medio por 
parte de los usuarios. A partir de estos informes podemos reconocer algunas constantes o las transformaciones en la relación del usuario con la creación de contenidos para su difusión online.

La propia introducción de nuevas preguntas en las encuestas realizadas por la AIMC ponen el foco de atención en los fenómenos surgentes entre los internautas, al tiempo que abadona otros. Hemos tomado como orquilla para analizar la evolución de la implicación ciudadana en la generación de contenidos los años que van de 2005 a 2013. La elección de 2005 como año de inicio seleccionado responde a la introducción de nuevas e influyentes herramientas UGC (User Generated Contents, contenidos generados por usuarios). En 2005 comienza a funcionar YouTube, al tiempo que Mark Zuckerberg registra el dominio facebook.com (eliminando el artículo "The" de su denominación previa) e inicia su expansión por Reino Unido. Es en 2006 cuando Tim O'Reilly define el concepto de Web 2.0, haciendo referencia a otros servicios y plataformas que llevaban varios años en funcionamiento (como Wikipedia, desde 2001).

La primera implicación activa del usuario vino de la mano de la creación de webs personales. El informe Navegantes en la red preguntó a los usuarios si disponían de web personal hasta 2011. En 2005 respondía afirmativamente el 21,3\%, en 2006 el $20,3 \%$, en 2007 el 19,2\%, en 2008 el 17,7\%, en 2009 el $16,3 \%$, en 2010 el $17,9 \%$ y en 2011 el 15,4\%. Llegamos así a la conclusión de que un medio ya de por sí minoritario lo es aún más con el avance de los años, reduciéndose en siete años casi seis puntos. La creación de una web personal requería el conocimiento de las herramientas informáticas o la contratación de los servicios de un webmaster, por más que progresivamente fueran simplificándose los procesos de edición y gestión de un sitio web.

La progresiva reducción de usuarios que cuentan con una página propia no se produce a causa del desinterés por encontrarse presente en la web, sino que este tipo de formato es sustituido por otros muchos más intuitivos, expandidos y económicos como son los blogs, en un primer momento, y por las redes sociales, más adelante. Podríamos así afirmar que a la primera fase de espacios personales basada en la posesión de una web personal sigue una segunda marcada por el desarrollo e implementación de los blogs personales, seguida por una tercera fase en la que la personalización de los contenidos divulgados se realiza a través de redes sociales.

Navegantes en la red interroga a los usuarios acerca de su relación con los blogs y pregunta si cuentan o no con un blog propio y si publican contenidos frecuentemente, ocasionalmente o no lo actualizan. Los resultados muestran una evolución paralela a la posesión de una web personal, aún más clara si atendemos a la frecuencia de actualización. En 2005 cuenta con un blog el 27,2\% de los usuarios encuestados, en 2006 el 31,9\%, en 2007 el 35,2\%, en 2008 el 34,1\%, en 2009 el 32,2\%, en 2010 el $28,1 \%$, en 2011 el $25,2 \%$, en 2012 el $22,6 \%$ y en 2013 el $23,2 \%$. A pesar de la evolución ascendente hasta 2007, desde 2008 se inicia un descenso progresivo, coincidente con el inicio del fenómeno de las redes sociales, la expansión de Facebook en castellano y la consolidación de Tuenti, que fue lanzado a finales de 2006. Apuntemos, en todo caso, el ligero despunte que con respecto al año anterior tienen los blogs en 2013. 
En cuanto al porcentaje de usuarios que actualizan su blog con frecuencia, la evolución es la siguiente: en 2005 lo hace el 6\%, en 2006 el 7,2\%, en 2007 el 9\%, en 2008 el 8,8\%, en 2009 el 7,1\%, en 2010 el 7,4\%, en 2011 el 6,1\%, en 2012 el 4,8\% y en 2013 el 5,1\%. El compromiso con la generación de contenidos publicados a través de web se reduce de forma paralela a la propia utilización del blog, de donde podemos concluir que el medio pasa de moda o su lugar es ocupado por las redes sociales, también por parte de los usuarios más activos en la publicación. De nuevo en 2013 los datos han subido apenas tres décimas.

Atendiendo a la evolución del interés que Facebook, Tuenti y Twitter despierta entre los usuarios españoles, haciendo una búsqueda de los tres conceptos a través de Google Trends, podemos observar que el fenómeno de las redes sociales arranca con fuerza en España entre 2008 y 2009, muy especialmente desde 2009, y mantiene sus cotas de crecimiento hasta diciembre de 2012, momento a partir de cual se reducen drásticamente las búsquedas en Google de los términos Facebook y Tuenti. Sólo Twitter, aun con un seguimiento más minoritario a las otras dos redes, parece mantener sus resultados sin importantes crecimientos, de donde podemos deducir que el ciclo de expansión de estas redes se ha estancado (o ha madurado). Apuntemos, en todo caso, que Google Trends hace un seguimiento de los términos introducidos en las búsquedas de Google, que no tiene por qué traducirse como un desinterés hacia las redes sociales. Estas cuentan con aplicaciones propias y los usuarios recuerdan sus direcciones URL, con lo cual no precisan de su búsqueda a través de Google. Los navegadores contribuyen además a facilitar el acceso a las páginas más visitadas, con lo que Google deja de ser el medio de acceso a aquellas.

La AIMC comienza a preguntar a los españoles por su presencia y uso de las redes sociales a partir de 2008. Este año tenemos que el 52,7\% de los usuarios está registrado a alguna red social, dato que se eleva al $71,6 \%$ en 2009 , el $84 \%$ en 2010 , el $87,3 \%$ en 2011 , el $88,6 \%$ en 2012 y el $90,3 \%$ en 2013 . De entre los usuarios que están registrados en alguna red social, la primera es, de forma indiscutible, Facebook, con un $61,7 \%$ de aquellos en 2008 , un $71,6 \%$ en 2009 , un $89,9 \%$ en 2010 , un $89,8 \%$ en 2011, un $90,5 \%$ en 2012 y un 90,3\% en 2013. Podemos concluir que Facebook se ha convertido en la principal marca que pone a los usuarios en relación entre sí tejiendo redes sociales entre ellos.

En la evolución de la relación de los internautas españolas entre 2005 y 2013 con los portales UGC descubrimos que, al menos hasta ahora, ninguna herramienta ha prolongado indefinidamente una posición prioritaria entre los usuarios, y que sus intereses han variado con la introducción de nuevos servicios y herramientas que podían responder mejor a sus demandas, sin que ello implicara la desaparición del formato previo. Así, de la web personal, muy limitada en expansión, se pasó a la publicación de blogs, que como fenómeno podemos calificar de moda pasajera entre las audiencias masivas, a pesar de consolidar algunos referentes. De ahí se pasó a las redes sociales. Estas últimas podemos entenderlas como una plataforma, o un "pan-formato" que engloba las herramientas anteriores de creación de contenidos y que garantiza un mayor seguimiento y fidelidad de la comunidad de usuarios relacionados entre sí. Aunque a Facebook le quedan otros mercados, esta tendencia de involución de la 
marca a nivel global ha llevado a un analista de la compañía Ironfire Capital, Eric Jackson, a afirmar que la red social desaparecería antes de 2020 (Thompson, 2013).

Por lo que aquí nos interesa, la implicación del usuario en la generación de contenidos, Navegantes en la red también ha preguntado desde 2008, como parte de la mayor atención a la actividad del internauta, acerca de su aportación de contenidos a la Web. En 2008 subió contenidos "a la web a nivel personal" el 46\% de usuarios, la mayor parte de ellos fotos (un 32,9\%); en 2009 esta cifra se reduce ligeramente al $44,7 \%$ (con un $32,4 \%$ que sube fotografías); en 2010 sin embargo crece al 52,5\% (estamos en el inicio del fenómeno de las redes sociales en España) y un 39,4\% de usuarios sube fotos; en 2011 sube contenidos el 57,9\%, de los cuales la mayor parte comentarios u opiniones (en un 41,1\%), cuestión introducida por primera vez este año en la encuesta, seguida de un $38,1 \%$ que publica fotos; en cuanto a 2012, el valor es inferior a 2011, siendo del 55,5\% el total de usuarios que sube contenidos personales, siendo de nuevo el mayor porcentaje (un 39,8\%) opiniones, seguido de un $37,4 \%$ que sube fotografías, valor también inferior a 2011. En 2013 reconocía tener bastante actividad en las redes sociales un $22,3 \%$, frente a un $40,3 \%$ con algo de actividad y un $36,9 \%$ de poca o ninguna actividad. Si trasladamos la fórmula 90-9-1 al uso de redes sociales en España, esta sería 37-40-22, donde queda manifiesto que los usuarios activos siguen siendo minoritarios pero también que los otros han incrementado su participación.

El inicio de la tendencia a la baja en el seguimiento de redes sociales, que se sitúa en España a partir del otoño de 2012, ha parecido venir acompañado de una reducción en la publicación de contenidos de carácter personal, en lo que podríamos entender como un inicio de decadencia de las redes sociales y una nueva muestra del agotamiento de un soporte orientado a recoger contenidos creados por los usuarios.

Podríamos así concluir que las herramientas y servicios de creación y divulgación de contenidos personales no han interesado de forma continuada de forma masiva, de donde deducimos la caducidad de las marcas UGC. Las diversas plataformas sociales de Internet se convierten así en servicios marcados por su escasa perdurabilidad en el tiempo, como sucesión de diferentes marcas con mayor o menor auge pero nunca permanentes.

\section{Resultados (II): El alcance de los medios de los usuarios}

Esta línea de argumentación de nuestra hipótesis se nos revela menos eficaz que la anterior, desde el momento en que los datos que tenemos acerca de la audiencia de los sitios web son parciales y relativos únicamente a aquellos portales con mayor seguimiento. Paradójicamente, los editores y gestores de un portal saben con precisión el tráfico y cobertura de sus contenidos, si bien no los hacen públicos desde el momento en que no comunicar dicha información puede beneficiarlos a la hora de negociar publicidad u ocultar posibles reducciones de seguimiento por parte de usuarios. Como en la comercialización de otro tipo de productos, las empresas de comunicación silencian los resultados en la divulgación de sus contenidos.

En el caso preciso de YouTube, como hemos dicho, estos datos dejaron de ser públicos con la adquisición por parte de Google. Acerca del alcance de los documentos 
de vídeo dentro de YouTube, la empresa Viral Manager (2011) estudiaba el porcentaje de visionados medios que podía llegar a tener un vídeo, llegando a la conclusión de que el $70 \%$ de los vídeos tenía al menos 20 visualizaciones, pero que menos del $10 \%$ tenía más de 1.500 visualizaciones, siendo alrededor del $1 \%$ el número de vídeos compartidos aquellos llegaban a las 500.000 visualizaciones.

Pérez Rufí (2011: web) llegaba a la conclusión de que eran los principales medios y marcas las que concentraban un mayor volumen de visitas de sus contenidos. Desde el momento en que los usuarios hacen de las piezas creadas por la industria sus favoritas, está mostrando también su preferencia por los vídeos creados por profesionales, en lugar de la ingente cantidad de material amateur de que ocupa horas y horas de vídeo y espacio de almacenamiento en los recursos del canal. Subsiste el usuario que hace un uso del canal para difundir sus vídeos, pero queda relegado a un plano secundario, dada la utopía de la horizontalidad: el usuario cuenta con la tecnología para producir y con el canal para difundir, pero no con la potencia del marketing de la industria audiovisual tradicional.

Si consultamos el índice Alexa.com, que incluye los listados de los sites más visitados por países, los datos podrían hacernos dudar hasta el punto de negar la hipótesis que origina nuestra investigación. Según Alexa, en 2014 la red social Facebook es la tercera web más visitada en España después del buscador Google en sus versiones .com y .es, seguida de YouTube en cuarta posición y Twitter en la quinta. La primera marca de un medio no nacido digital que se introduce en el listado es Marca.com (décima posición), seguida de Elmundo.es (undécima posición) y Elpais.com (duodécima posición).

Estos datos situarían potencialmente a plataformas creadas por y para usuarios por delante de los medios digitales asociados a la prensa en España y recuperaría la centralidad que hemos negado en el anterior apartado al usuario generados de contenidos. Con todo, hemos de advertir que el consumo masivo de Facebook, YouTube o Twitter no cuestiona la posición de los medios informativos, aunque suponen nuevos e importantes agentes dentro de las industrias culturales que se sirve de la producción del usuario.

Debemos, además, recuperar argumentos ya desarrollados: los contenidos más consumidos en plataformas como YouTube han sido producidas por las grandes industrias culturales. Crece el número de canales creados por usuarios con suscripciones millonarias, subvencionados por la propia plataforma de Google, y su presencia domina los listados de vídeos más reproducidos día a día. No obstante, las listas de mayor número de reproducciones globales se llenan de contenidos creados por las grandes discográficas multinacionales, las majors de Hollywood y formatos televisivos de amplio seguimiento.

Llevado a la comparativa entre el alcance de los medios de información digitales ligados a la prensa convencional y el de los medios creados por usuarios, podemos generalizar señalando que el compromiso del usuario con la creación de información de actualidad habrá de ser por fuerza mucho más limitado. Ello nos llevaría a la idea de que las marcas de referencia de los usuarios en su búsqueda de contenidos de actualidad se identificarán antes con las de los medios informativos consolidados en el imaginario del usuario, dada la mejor capacidad de respuesta de tales medios a la 
inmediatez en la publicación de las informaciones, el prestigio que cabría suponerle y la amplitud de temas recogidos. Como apunta Martin Hirst (2011: 125), el periodismo industrial sigue siendo el paradigma dominante.

\section{Conclusiones}

La naturaleza de la Web 2.0 como espacio para la interacción y la colaboración entre usuarios en la generación de contenidos ha topado con la realidad de una industria que no quiere dejar al usuario las riendas del negocio en materia informativa, para así mantener su oferta de productos. El usuario sin la fuerza de las campañas de marketing de la industria ni una "cartera" de suscriptores millonarios tendrá más difícil la divulgación de contenidos de una forma masiva. El posicionamiento de marca de los medios que el ciudadano conoce por diversas plataformas paralelas es muy superior al de los medios que el usuario crea. Es cierto que el usuario tiene una posición central en Internet, pero antes como audiencia receptora de unos contenidos que como productor de los mismos.

Conscientes de las demandas de interacción del usuario y de personalización de la oferta, las industrias culturales se han adaptado a aquellas solicitudes para ofrecer al usuario un producto que le satisfaga. El usuario que accede a las redes sociales o plataformas UGC, con las que se ha relacionado desde la intimidad y cotidianeidad que le han transmitido otros usuarios integrantes de la comunidad 2.0, encuentra así un medio que intenta mantener la apariencia de red creada por y para el usuario en lugar de la red comercial integrada dentro de las industrias culturales, en general, y de las grandes corporaciones multimedia, de forma particular. Si no como parte de un conglomerado (véase el caso de Facebook), sí como nuevo agente con una importante influencia en el mundo de las comunicación. Hablamos, por tanto, de nuevas marcas masivas o de nuevos agentes que vienen a ocupar el lugar de los medios, apoyados esta vez por los usuarios.

A raíz de los datos y los argumentos expuestos, consideramos demostrada nuestra hipótesis de que la participación ciudadana en la creación de contenidos culturales, de forma genérica, o de información, de forma particular, no supone una amenaza para las industrias de la comunicación. Sostenemos esta afirmación tanto desde la minoritaria vinculación del usuario en la producción como en el limitado alcance de sus propuestas.

Esta situación resultaría paralela a la de toda la producción independiente, dado que el alcance de medios y productos será muy inferior, al no contar con la inversión y las herramientas de marketing y comercialización con que cuentan los grandes grupos. Se da el caso, tan paradójico como lógico, de que aquellos servicios creados por usuarios que crecen en alcance convirtiéndose en nuevos e influyentes proveedores de contenidos, llegan a integrarse dentro de las grandes corporaciones de comunicación cuando estos crecen, como actores con una posición consolidada en el mercado de las comunicaciones. Sería el caso de MySpace, adquirido por News Corporation en 2007, o de YouTube, comprado por Google en 2006; las plataformas se integran en las industrias culturales establecidas con más poder y se controla de esta forma el alcance de la producción del usuario. Aquellos que no se integren en estos grupos podrán sobrevivir con 
bastantes dificultades, pero lo harán con una vocación minoritaria y conscientes de su marginalidad como medios independientes.

Creemos pues que en un mercado dominado por los grandes grupos de comunicación, ya sean convencionales o digitales, la actuación del usuario y la creación de contenidos por parte del mismo no supone un verdadero rival para los medios informativos, razón por la cual el periodismo ciudadano no supone una amenaza para la industria de la prensa.

Jones y Salter (2012: 173) afirman que el futuro del periodismo está en integrar todo lo que proporciona el mundo digital para mejorarlo y renovar el periodismo a las generaciones que vienen. La diferencia entre los amateurs y los profesionales de la información vendrá de manos de la excelencia. Hirst (2011: 205) apunta de nuevo a la causa de la crisis en el sector por la pérdida de la confianza y la credibilidad en aquellos. Podemos así concluir que la raíz del problema en el medio no procede tanto de "amenazas externas" (como la actuación del usuario en la generación de contenidos culturales o informativos), como de las debilidades internas del sector relacionadas con la relación entre el medio y la audiencia, dado el supuesto detrimento de la percepción del periodismo industrial por parte del ciudadano.

\section{Referencias bibliográficas}

AIMC (2005-2014): "Navegantes en la red. Encuestas AIMC a usuarios de Internet": http://www.aimc.es/-Navegantes-en-la-Red-.html [Consulta: 5 de septiembre de 2014].

AIMC (2012): "Audiencia de Internet en el EGM. Abril-Mayo 2012": http://www.aimc.es/spip.php?action=acceder_document\&arg=2143\&cle=3c914aa adbab92082a1 ea38704d04ab0f3635294\&file $=$ pdf\%2Finternet212.pdf [Consulta: 5 de septiembre de 2014].

BRUNS, Axel y HIGHFIELD, Tim (2012): "Blogs, Twitter, and Breaking News: The Producer of Citizen Journalism", en LIND, Rebecca Ann (Ed.): Producing Theory in a Digital World: The Intersection of Audiences and Production in Contemporary Theory. New York, Peter Lang Publishing Inc., pp. 15-32.

CASTELLS, Manuel (2009): Comunicación y poder. Madrid, Alianza.

FICO, Frederik, LACY, Stephen, WILDMAN, Steven S., BALDWIN, Thomas, BERGAN, Daniel; \& ZUBE, Paul (2013): "Citizen Journalism Sites as Information Substitutes and Complements for United States Newspaper Coverage of Local Governments". Digital Journalism, num. 1, pp. 152-168. En: http://www.tandfonline.com/doi/abs/10.1080/21670811.2012.740270\#.UaEAEZzcN8o [Consulta: 5 de septiembre de 2014].

HIRST, Martin (2011): News 2.0: Can journalism survive the Internet? Crows Nest, Allen \& Unwin.

JENKINS, Henry (2007): "Nine Propositions Towards a Cultural Theory of YouTube". Confessions of an Aca-Fan: http://www.henryjenkins.org/2007/05/9_propositions_towards_a_cultu.html [Consulta: 5 de septiembre de 2014]. 
JONES, Janet y SALTER, Lee (2012): Digital Journalism. Los Ángeles, SAGE Publications.

KATZ, James E. (2011) "Communication perspectives on social networking and citizen journalism challenges to traditional newspapers". Periodica Polytechnica, Vol 19, num. 2. Budapest University of Technology and Economics, pp. 51-62: http://www.pp.bme.hu/so/article/view/1581 [Consulta: 5 de septiembre de 2014] DOI: $10.3311 /$ pp.so.2011-2.01

KEEN, Andrew (2007): The Cult of the Amateur: How Today's Internet is Killing Our Culture. New York, Doubleday / Currency.

NIELSEN, Jakob (2006): "Participation Inequality: Encouraging More Users to Contribute", en Useit.com: http://www.useit.com/alertbox/participation_inequality.html [Consulta: 5 de septiembre de 2014].

PÉREZ RUFÍ, José Patricio (2011): "YouTube ya no es “tu televisión”: cultura colaborativa y red comercial en el vídeo online". Revista Internacional de Comunicación, $\mathrm{n}^{\mathrm{o}}$ 11. Departamento de Comunicación Audiovisual, Publicidad y Literatura, Universidad de Sevilla, pp. 146-162: http://www.revistacomunicacion.org/pdf /n9/monografico/M11.-YouTube_ya_no_es_tu_television_cultura_colabora-

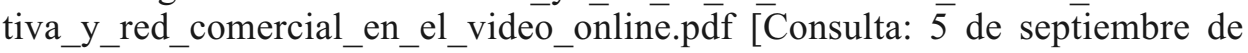
2014].

PUENTE, Soledad y GRASSAU, Daniela (2011): "Periodismo ciudadano: dos términos contradictorios. La experiencia chilena según sus protagonistas". Palabra Clave, $\mathrm{n}^{\circ}$ 14. Universidad de La Sabana, Bogotá: http://www.scielo.org.co /scielo.php?pid=S0122-82852011000100009\&script=sci_arttext [Consulta: 5 de septiembre de 2014].

PELLEGRINI-RIPAMONTI, Silvia (2010): “Análisis conceptual del Periodismo Ciudadano y propuesta metodológica para analizar su contribución informativa". $\mathrm{Pa}$ labra Clave, $\mathrm{n}^{\mathrm{o}}$ 13. Universidad de La Sabana, Bogotá, pp. 271-290: http://palabraclave.unisabana.edu.co/index.php/palabraclave/article/view/1764 [Consulta: 5 de septiembre de 2014].

PERCEVAL, José María (2008): "El estado líquido del ciberperiodismo". Anàlisi: quaderns de comunicació y cultura, $\mathrm{n}^{\circ}$ 36. Universitat Autònoma de Barcelona, Servei de Publicacions, pp.79-86: http://ddd.uab.cat/pub/analisi/02112175n36 /02112175n36p79.pdf [Consulta: 5 de septiembre de 2014].

SÁEZ VACAS, Fernando (2007): "Vida y sociedad en el Nuevo Entorno Tecnosocial", en FUMERO, A. y ROCA, G. Redes Web 2.0. Fundación Orange España: http://www.fundacionorange.es/areas/25_publicaciones/WEB_DEF_COMPLETO.pdf [Consulta: 5 de septiembre de 2014].

TANCER, Bill (2008): Click, What Millions of People Do Online and Why It Matters. Hyperion Ebook.

THOMPSON, Cadie (2013): "Facebook Will Disappear in 5 to 8 Years: Analyst", en CNBC: http://www.cnbc.com/id/47674474 [Consulta: 5 de septiembre de 2014]. 
VIRAL MANAGER (2011): "How many views should you expect for a YouTube video?", en Viral Manager: http://www.viralmanager.com/strategy/research_documents/how-many-you-tube-views-in-first-month.pdf [Consulta: 5 de septiembre de 2014]. 